\title{
O TRABALHO DOCENTE NO ENSINO SUPERIOR: DESAFIOS FRENTE À GERAÇÃO Y
}

Ines Cristina Giometti, Alba Regina Azevedo Arana, Elisangela Bulla Ikeshoji

Universidade do Oeste Paulista - UNOESTE, Presidente Prudente, SP. e-mail: inesgiometti@unoeste.br

\section{RESUMO}

Com as mudanças políticas, econômicas, sociais e tecnológicas surgem gerações que compartilham características próprias daquele tempo e contexto em que viveram. A geração que hoje frequenta os bancos universitários é conhecida como geração $Y$, que já cresceram conectados à internet. Os jovens dessa geração costumam ser imediatistas, impacientes, não lidam bem com críticas, querem um retorno constante e são menos comprometidos. Enfrentar uma geração diferente em uma sala de aula, que está acostumada com a informação rápida da internet, sempre conectada a um celular e que facilmente se aborrece com a forma tradicional de ensino é um desafio a ser enfrentados pelos docentes na atualidade. Portanto, o objetivo do presente trabalho é apresentar uma reflexão sobre os desafios pedagógicos que os docentes universitários enfrentam em suas práticas diante da formação de uma nova geração (geração Y). Este trabalho irá apresentar as principais características das diferentes gerações; referenciar trabalhos que caracterizam a geração $Y$; analisar a importância do trabalho docente no ensino superior e refletir sobre as possibilidades de práticas pedagógicas que melhor atenda as necessidades da geração $Y$ em sala de aula. Procedimento metodológico utilizado para levantamento e elaboração dos dados se pautou em revisão bibliográfica, em livros e artigos científicos. Os principais resultados mostram que para esta geração de jovens universitários, há que se privilegiar a participação e o envolvimento do aluno no processo de ensino e de aprendizagem, buscando alternativas didáticas como resolução de problemas, trabalhos em grupo, elaboração de projetos criativos (maquetes, filmes, teatros e outros do gênero), além do uso das ferramentas multimídia (para uma maior comunicação virtual).

Palavras-chave: Geração Y; Ensino Superior; Trabalho Docente.

\section{WORK TEACHING IN HIGHER EDUCATION: CHALLENGES FACING THE GENERATION Y}

\begin{abstract}
With the political, economic, social and technological changes arise generations that share the characteristics of the time and context in which they lived. The generation that now attends college banks is known as Generation $Y$, who grew already connected to the internet. The younger generation are often sighted, impatient, do not deal well with criticism, want a steady return and are less committed. Facing a different generation in a classroom, which is used to the prompt information to the internet, always connected to a mobile and easily get bored with the traditional way of teaching is a challenge to be faced by teachers today. Therefore, the aim of this paper is to present a reflection on the pedagogical challenges that college teachers face in their practices before the formation of a new generation (Generation $Y$ ). This paper will present the main features of different generations; reference works featuring Generation Y; analyze the importance of teaching in higher education and reflect on the possibilities of teaching practices that best meets the needs of Generation $Y$ in the classroom. Approach used for survey and preparation of the data was based on literature review, scientific books and articles. The main results show that for this generation of college students, we must give priority to participation and student
\end{abstract}


involvement in the process of teaching and learning, seeking educational alternatives such as problem solving, group work, development of creative projects (models, movies, theaters and other gender), and the use of multimedia tools (for greater virtual communication).

Keywords: Generation Y; Higher Education; Teaching Work. 


\section{INTRODUÇÃO}

As dificuldades e os desafios encontrados durante o processo de ensino e de aprendizagem, com alunos de graduação, em diversas instituições, instigou a investigação sobre estudos desenvolvidos, com docentes e alunos da geração $Y$, no espaço da sala de aula.

E para tratar do assunto, tema da pesquisa o presente trabalho aborda as principais referências sobre as características das gerações que antecedem os membros da geração $Y$ (baby boomers e geração $X)$, da própria geração $\mathrm{Y}$ ou geração milênio e o que se sabe até o momento da próxima geração (geração Z). Aborda a geração $Y$ e a importância do trabalho docente no ensino superior.

Assim como apresenta também diferentes trabalhos já realizados que demonstram o pensamento dos jovens da geração $\mathrm{Y}$, mostrando os problemas encontrados quando há o encontro de gerações dentro da sala de aula, respeitando a importância do contexto pessoal, histórico, ambiental, social e econômico no desenvolvimento do indivíduo, e das características dos grupos de mesma faixa etária.

E por fim, faz uma reflexão sobre os desafios e possibilidades de ensinar em novas linguagens, novas narrativas, utilizando novos recursos, inovando com as práticas pedagógicas a partir do momento em que os docentes conseguem rever e analisar suas ações. Analisa-se também a importância do trabalho docente no ensino superior e o se reconhecer professor no exercício de sua profissão.

Sendo assim, o objetivo do presente trabalho é apresentar uma reflexão sobre os desafios pedagógicos que os docentes universitários enfrentam nas suas práticas diante da formação de uma nova geração (geração Y).

Portanto, busca-se verificar as lacunas existentes sobre o tema através de indagações, que tragam à tona soluções que sejam possíveis para as análises que serão feitas na pesquisa. As necessidades crescentes por práticas pedagógicas que de fato tragam melhorias no processo de ensino e aprendizagem são constantes e geram questões a serem discutidas, estudadas e analisadas, visando encontrar respostas para os desafios pedagógicos enfrentados pelos docentes universitários na sua prática, diante da formação de uma nova geração (geração Y).

Acredita-se que por meio dos estudos existentes do que já se conhece das características desta geração de alunos de nível superior, que cresceram envoltos pela comunicação virtual, poder-se-á chegar a 
métodos pedagógicos mais consistentes com a realidade educacional vivenciada hoje pelos docentes universitários. Entende-se que a reflexão na ação docente (SCHÖN, 1997) possibilita o desenvolvimento de métodos pedagógicos que melhor atende $\mathrm{o}$ desenvolvimento do processo de ensino e de aprendizagem.

Sendo assim, para o desenvolvimento dos estudos propostos a metodologia utilizada para realização da pesquisa pautouse de revisão bibliográfica, em livros e artigos científicos. Considerando que esta metodologia oferece a oportunidade de explorar e se aproximar dos vários estudos sobre o mesmo problema de pesquisa.

E para trilhar o percurso
metodológico inicia-se com a
contextualização das diferentes gerações.

\section{AS DIFERENTES GERAÇÕES E SUAS} CARATERÍSTICAS

É importante traçar características comuns entre os grupos de uma mesma geração, relatando as diferenças encontradas no perfil coletivo dos sujeitos de cada época, fruto da vivência histórica desses indivíduos.

Claro et al. (2010) relatam que a idade exata que caracteriza uma geração depende dos seus princípios de vida, sua visão, valores comuns, momentos históricos compartilhados e também as maneiras de se relacionar com 0 mundo. Entender 0 comportamento e a personalidade coletiva dos sujeitos de um determinado grupo etário é importante para definirmos ações educacionais condizentes com o estilo de aprendizagem dos mesmos.

Os membros da "geração $Y$ " ou "geração milênio" são as pessoas que nasceram no período compreendido de 1980 a 2000. A maioria dos estudantes de faculdades e das pós-graduações compõem este grupo, que cresceram em frente de telas eletrônicas como televisão, cinemas, vídeo games e monitores de computadores (WEILER, 2004) e que nos próximos anos comporão a força de trabalho, de renda e de consumo no Brasil (CLARO et al., 2010).

As gerações anteriores conhecidas como "baby boomers" (nascidos entre 1946 e 1964) e geração X (nascidos entre 1965 e 1980) quase não foram objetos de estudo no Brasil, porém a geração $Y$, devido a uma grande divulgação via "internet" tem sido alvo de estudos que demonstram que os jovens desta geração acreditam que os acontecimentos são imprevisíveis, pois viveram várias mudanças na sociedade (CLARO et al., 2010).

Segundo estudos realizados em outros países, os "baby boomers" cresceram em tempos de relativa prosperidade pósguerra e não vivenciaram os problemas das gerações atuais como o pessimismo geral, sequestros, poluição do meio ambiente e 
terrorismo. De maneira que tendem a aceitar o desenvolvimento e a mudança. Respeitam as autoridades e preferem ser considerados como iguais em uma organização. Diferente dos seus pais (geração dos Veteranos), não aceitam prontamente as regras estabelecidas no local de trabalho (CRAMPTON; HODGE, 2009).

Os membros da geração $X$ são menos leais ao empregador que nas gerações anteriores, mas não é uma deslealdade de todo negativa, pois tendem a aceitar mudanças, sobretudo tecnológicas, e, desde que sejam bem orientados em relação às metas, dedicam-se a melhorar o seu desempenho (FGI, 2006). Estes jovens ficaram conhecidos por conquistarem as chaves das portas de casa e, por isso, são bastante confiantes (BALC; BOZKURT, 2013).

A geração $Y$ conhecida também com a geração da "internet" tem sete traços exclusivos, segundo Howe e Strauss (1991), como: 1) são especiais (percebem toda a importância que as pessoas e mídia os dão); 2) são protegidos (até com assentos de carros especiais); 3) são confiantes (acreditam que serão melhores do que os seus pais); 4) orientados por comportamentos e atividades grupais (propensos a acompanhar os outros e a participar em atividades em grupo); 5) são convencionais (aceitam valores transmitidos pelos seus pais); 6) pressionados (tem horários para diferentes atividades durante o dia) e 7) focados (pensam desde cedo no futuro, em questões como carreiras e salários), (HOWE; STRAUSS, 1991; SIMÕES; GOUVEIA, 2008).

Os indivíduos da geração Y são os que mais estudaram, mais viajaram e tecnologicamente mais sofisticados de todas as gerações. Este grupo parece ser menos focado no resultado ou no processo, dando menos valor ao dinheiro, e a sua contribuição para a sociedade e seu papel familiar tem a mesma importância (CRAMPTON; HODGE, 2009).

Os jovens da geração $Y$ querem "trabalhar para viver" e não "viver para trabalhar", acreditam que longas horas de trabalho deterioram a qualidade de vida e que deve haver um balanço entre trabalho e lazer (BUCKLEY et al., 1998). Como vivenciaram seus pais trabalhando por muitas horas para posteriormente serem diminuídos, estes jovens querem ter uma vida mais equilibrada, podendo fazê-lo à custa de renda e de promoção (CRAMPTON; HODGE, 2009).

Macedo (2012) fez uma pesquisa com vários integrantes da geração $Y$ cursando os últimos anos de faculdade, brasileiros e estrangeiros, para verificar 0 que eles pensavam a respeito de uma futura carreira profissional. Neste trabalho foi verificado que não houve grandes diferenças entre jovens 
brasileiros e estrangeiros, nem entre homens e mulheres no que almejam profissionalmente, e realização no trabalho e estabilidade financeira foram os mais citados pelos jovens, seguido por boas relações sociais no emprego, e por último citaram prestígio.

Os jovens de hoje são mais independentes e mais liberais, pois cresceram em ambientes familiares não tradicionais, cerca de um em cada três tem pais separados e ambos trabalhando o dia todo, um em cada quatro tem uma família monoparental e três em cada quatro têm mães trabalhando o dia todo (IBGE, 2010), então tiveram certa independência, pois passavam algum tempo na creche ou em casa sozinhos.

Considerando que cresceram em ambientes com estruturas familiares diversificadas, não veem obstáculos quanto a diferenças culturais, de composição familiar ou estilos de vida (MITCHELL, 1993). Apesar de dominarem a tecnologia como ninguém, não tem muito sucesso com relações interpessoais e habilidades de comunicação como as gerações anteriores, pois são mais impacientes, e podem facilmente se entediar (DICECCO, 2006).

Como a maioria das necessidades dos jovens da geração $Y$ já foram supridas pelos seus pais, eles buscam a autorealização, demonstrando características como ambição, senso de justiça, franqueza, sendo informais mesmo com superiores, não sabem lidar com críticas ou falhas, querem equilíbrio entre lazer e trabalho e querem valorização constante dos seus supervisores (WOODRUFF, 2009).

A geração posterior à geração $Y$, ainda não chegou aos bancos universitários, conhecida como geração Z, são os nascidos em 2000 até a atualidade, são indivíduos que não podem ser considerados acelerados, pois já nasceram em ritmo de velocidade, com "internet" banda larga, Google, "smartphones", jogos "online", X-box (aparelho que contém jogos, acesso a internet, disponibilidade para CD, DVD) e outras tecnologias (CERBASI; BABOSA, 2009).

A tendência é que os indivíduos da geração Z estejam com fone nos ouvidos o tempo todo, enquanto realizam outras atividades e até mesmo assistindo a televisão, por isso, são chamados de "geração silenciosa". Rápidos e ágeis com computadores encontram dificuldades em escolas tradicionais e em relacionamentos interpessoais, pois a tecnologia presente a todo instante dificulta a comunicação verbal. Ainda não se sabe como estes indivíduos irão lidar com o ambiente de trabalho ou com o estudo na educação superior (NETO; FRANCO, 2010). 
Para melhor compreensão do estudo proposto neste artigo, aborda-se a seguir a geração $Y$ no contexto do ensino superior.

\section{GERAÇÃO Y NO ENSINO SUPERIOR}

O comportamento dos jovens está intimamente relacionado com as condições sociais e econômicas, e por isso, jovens de uma mesma região geográfica tem comportamentos similares diferindo de jovens de outros continentes, porém as preferências e as expectativas em relação ao futuro fruto de experiências similares num dado momento histórico, são comuns entre os jovens de diferentes nacionalidades (SANTOS, 2004).

É o que menciona Santrock (1998) com relação ao comportamento em se tratando de aspectos espaciais e temporais, assim como estímulos e o desenvolvimento, que os membros de um grupo de pessoas têm experiências similares que os fazem únicos quando comparados a qualquer outro grupo.

Atualmente, com a globalização da tecnologia, os valores dos jovens brasileiros seriam semelhantes aos dos americanos, sendo possíveis associações na forma de agir das duas populações (MOTTA; GOMES; VALENTE, 2009).

Apesar do compartilhamento da tecnologia entre os jovens, é importante ressaltar que as características de uma geração, nem sempre são as mesmas dependendo da classe social em que este se encontra. Rocha-de-Oliveira et al. (2012, p. 555) tecem a seguinte consideração:

Considerar que todos os jovens que nasceram em determinado período pertencem a um único grupo como tem sido caracterizada a Geração Y é esquecer as diferenças regionais e desigualdades sociais da juventude brasileira. Alguns poderiam se enquadrar neste perfil, mas trata-se de uma minoria frente à grande parte de jovens que, apesar da existência de redes sociais, internet, enfim, tecnologias que deveriam aproximá-los deste modelo, por vezes, reforçam a distância que se pretende eliminar. A juventude, portanto, não é um grupo único, sendo formado por uma diversidade de grupos que trazem consigo particularidades regionais, étnicas e culturais. As juventudes brasileiras são diversas, sendo necessária conhecê-las para dar a correta dimensão do grupo que se está analisando.

Kliksberg (2006) destaca a diferença nas trajetórias vivenciadas, oportunidades ancoradas, entre os jovens de diferentes classes sociais da América Latina. Os jovens de classes mais ricas recebem níveis elevados de educação, saúde, trabalho e habitação, se assemelhando mais aos jovens de países 
desenvolvidos, enquanto os jovens carentes têm poucas possibilidades de educação e trabalho.

Portanto, na realidade brasileira, as referências feitas à geração $Y$ se dirigem aos jovens de estrato superior da sociedade, não representando a totalidade dos jovens brasileiros (ROCHA-DE-OLIVEIRA; PICCININI; BITENCOURT, 2012).

Sendo relevante observar que apenas uma pequena parcela (14\%) da população (PNUD, 2010) alcança grau de instrução no ensino superior, e que geralmente são jovens privilegiados em sua situação financeira, é importante conhecer as características desta geração.

Santos (2004) em sua tese de doutorado fez um estudo com a população de jovens de diferentes partes do mundo, incluindo pessoas de alguns países da Europa, da Ásia e da África para verificar valores e expectativas compartilhadas entre os jovens. Neste estudo, (SANTOS, 2004, p. 87) concluiu que:

Embora no segmento jovem da população seja possível identificar vários grupos consoantes os diferentes comportamentos, opções, expectativas e ambições, eles sobrepõem-se quando analisados em conjunto ou quando consideradas como um todo, demonstrando a tendência para a homogeneidade.
Moses (2000) ressalta que o aumento na disponibilidade da informação, das comunicações, das imagens e dos meios tecnológicos irá permitir a permuta de gostos e hábitos entre os indivíduos até atingir a convergência destes aspectos nos diferentes grupos, mantendo as diferenças entre opções de vida que são próprias das personalidades de cada indivíduo.

Frente a este cenário se desenvolve o trabalho docente, no ensino superior.

\section{ENSINO SUPERIOR: O TRABALHO DOCENTE}

Os docentes que atuam no ensino superior vivenciaram também o início da modernização tecnológica, pois estavam ligados a sua formação profissional no período universitário, mas diferente da geração $Y$ que nasceu no contexto das grandes inovações na área da tecnologia.

As tecnologias estão postas no cotidiano e o docente precisa lidar com este elemento na sua prática pedagógica. É preciso que o docente dê continuidade e sobrevivência aos estilos pedagógicos tradicionais, mas isto não impede de utilizarse em sua prática de elementos novos e modernizadores (LUCARELLI, 2007).

Acrescentar elementos novos nas práticas pedagógicas é essencial para atender as necessidades da geração $\mathrm{Y}$, esta que vive no momento histórico uma interferência ilimitada de informações. Por isso, a 
importância do docente interromper uma prática que se repete o tempo todo, se ela não estiver funcionando, inovar é recomendável. Todavia é o que Heller apud Lucarelli $(2007$, p. 81) menciona como "práxis inventiva, é aquela que inclui sempre a produção de algo novo".

Realmente ser docente é atuar na complexidade das relações humanas. Para enfrentar este desafio da profissão docente, segundo Tardif (2010), o docente precisa compreender a importância dos saberes profissionais, disciplinares, curriculares e experienciais.

O saber experiencial é que permite o docente analisar sua prática, refletir suas ações de modo que sua ação pedagógica atenda as necessidades de cada turma. A educação no ensino superior não deve somente instruir, mas conduzir a construção de novos conhecimentos.

Conforme complementa Leite e Ramos (2007), a educação deve ser problematizadora, que conduza o aluno ao desenvolvimento da consciência da consciência, para intervir na problemática social. E para isto, o docente precisa se reconhecer com sujeito desta realidade, colocando em práticas seus saberes docentes.

O docente precisa tomar ciência da relevância destes saberes, para não se limitar ao que os autores Leite e Ramos (2007, p. 31) aborda, "a docência universitária ainda continua a ter como exigência privilegiada (e quase exclusiva) a competência científica descurando a competência pedagógicadidática".

Entende-se, portanto, que o docente ao exercer sua profissão, articulando seus saberes docentes propiciados pela experiência nas ações pedagógicas e conhecendo as características da geração $\mathrm{Y}$, pode enfrentar os desafios relacionados ao processo de ensino e de aprendizagem.

E assim, a partir do percurso metodológico apresentado a seguir, serão abordados os desafios docentes frente à geração $\mathrm{Y}$ e as possibilidades de superar os desafios educacionais.

\section{PERCURSO METODOLÓGICO}

A metodologia utilizada para realização da pesquisa pautou-se de revisão bibliográfica, em livros e artigos científicos. Considerando que este tipo de pesquisa oferece a oportunidade de explorar vários estudos sobre o mesmo problema de pesquisa.

O caminho adotado para organizar este artigo seguiu os seguintes passos: 1) elaboração do problema de pesquisa; 2) possíveis respostas à questão; 3) levantamento da bibliografia; 4) levantamento das informações contidas na bibliografia; 5) análise crítica das informações 
contidas nos documentos; 6) reflexão dos dados obtidos para proposições de possíveis soluções.

Portanto, apresenta-se a seguir, as pesquisas desenvolvidas com jovens da geração Y.

\section{PESQUISAS SOBRE A GERAÇÃO Y}

Neste momento serão apresentadas as pesquisas realizadas em diferentes países, em que os sujeitos eram membros da geração $Y$, docentes ou estudantes, retratam a maneira em que vivenciaram a educação e a busca pelo conhecimento.

Considerando que o pensamento crítico é crucial para o processo de aprendizado, para desenvolver a inteligência cognitiva e para a busca pelo conhecimento ser efetiva (WEILER, 2004). A questão do pensamento crítico não pode ser separada de como os jovens veem seu universo de informação.

Em uma pesquisa com jovens da Universidade de Grinnell, eles foram questionados sobre a sua percepção em relação à discussão de temas divergentes e polêmicos no Campus universitário e somente $2,5 \%$ acreditam que o debate seja uma forma de adquirir novas informações (TROSSET, 1998). Em debates com os pares, os estudantes raramente dividem novas informações que eles mesmos localizaram independentemente, ou novas opiniões formuladas usando novas informações, métodos que requerem extensivo uso de habilidades de pensamento crítico (TROSSET, 1998).

Além disso, neste estudo, há uma forte tendência em favor do conhecimento oriundo de experiências pessoais ou de experiências relatadas por outros em detrimento da informação oriunda de estudos de pesquisas ou estatísticas. Somente $13 \%$ dos estudantes entrevistados consideram a informação de estudos científicos importante como origem do seu conhecimento. Os estudantes relataram, ainda, que não gostam de ter seus conhecimentos e ou opiniões desafiados ou contestados (TROSSET, 1998).

Uma pesquisa realizada com estudantes da Universidade de Idaho demonstrou que para eles as prioridades na busca pela informação são a facilidade de uso, a exatidão, a atualidade, a disponibilidade e o custo. Em segundo lugar no grau de importância para os alunos foram confiança, qualidade, credibilidade, validade, abrangência e se a informação era completa (YOUNG; SEGGERN, 2001).

Considerando que no passado os obstáculos para obter informação eram simplesmente a indisponibilidade do livro da biblioteca, por estar emprestado ou não ter muitos volumes, atualmente os obstáculos citados pelos estudantes deste estudo foram 
excesso de informação e credibilidade questionável do "site" (YOUNG; SEGGERN, 2001). Só de questionarem as informações obtidas pela "internet" já traz uma boa perspectiva em relação a estes alunos e é também um indicativo de sua visão pluralista. Pois tem sido demonstrado que os alunos da geração $\mathrm{Y}$ tendem a superestimar suas habilidades de encontrar informações na “internet" (GRIMES; BOENING, 2001).

$\mathrm{Na}$ pesquisa de Young e Seggern (2001) ficou clara a preocupação dos alunos no tempo gasto para a localização da informação, pois eles poderiam usar este tempo em outras atividades que eles julgam serem mais importantes (um dos estudantes relatou jogos como exemplo).

De 40 a $50 \%$ dos sujeitos de um estudo de 1999 usavam a "internet" semanalmente (D'ESPOSITO; GARDNER, 1999), já em 2001, foi constatado que $73 \%$ das faculdades americanas aceitavam a busca de informação dos estudantes na "internet" sem se preocupar com a qualidade dos "sites" que os alunos estavam usando (HERRING, 2001).

Foi realizado um estudo com alunos de vários cursos de Licenciatura de Aracaju, com a finalidade de verificar se estes alunos, futuros docentes, tem dado a devida importância ao uso de ferramentas de informação e comunicação. Dos entrevistados, $58,62 \%$ se consideram mal informados do que acontece no mundo e atribuem a falta de tempo como responsável por isso, 58,1\% utilizam-se da "internet" como principal ferramenta de notícias, $42,6 \%$ utilizam redes sociais (principalmente "Facebook") para se comunicarem com outras pessoas, seguido por $39,8 \%$ que utilizam o celular, todos os entrevistados tem acesso à "internet", sendo que 70,5 \% a utilizam sempre e acessam a rede de casa.

Porém, quando questionados sobre o uso dessas ferramentas em sala de aula, estes alunos acreditam que ainda está distante de acontecer isso na prática, mostrando que os docentes ainda estão despreparados para o uso dessas ferramentas como instrumento de ensino (BARBOSA; FERREIRA, 2013).

Os alunos da geração $Y$ de quatro Instituições de Ensino de Ciências Contábeis foram questionados em um estudo sobre o que eles consideram ser um bom docente, e o resultado indicou que o mais importante para eles ainda é o domínio do conteúdo e a facilidade de explicá-lo. Ter um bom relacionamento com os alunos e utilizar tecnologia em sala de aula também foram requisitos citados pelos alunos para o que eles consideram um bom docente.

Atributos pessoais (beleza, tom de voz, asseado ou ter uma letra legível), motivação e exigência do docente foram menos citados como qualidades de um bom 
docente (NOGUEIRA; CASA NOVA; CARVALHO, 2012).

Em um estudo analisando docentes do ensino básico da Turquia, das gerações X e $Y$, demonstrou que a geração $Y$ quer menos regras nas escolas, quer usar mais tecnologia, não gostam de trabalho em equipe, não tendo paciência para reuniões e tem menos compromisso organizacional em relação à geração X.

Além disso, respeitam os colegas não pela experiência, mas se os mesmos possuam ações que mereçam respeito. Os docentes da geração $Y$ veem seus empregos como ferramenta para pagar suas contas, trabalhando duro só quando necessário e preferem aprender habilidades via computador, dispensando aconselhamento (BALC; BOZKURT, 2013).

Portanto, se faz necessário o docente reconhecer-se em sua profissão, pois sem isto, não é possível desenvolver a complexidade que seu trabalho exige.

\section{DESAFIOS DOCENTES FRENTE A GERAÇÃO Y}

O docente ao se reconhecer no exercício de sua profissão, realizando formação continuada, tem condições de lidar com seus conflitos e desempenhar melhor sua ação pedagógica no ambiente escolar. Sendo assim, serão apresentados no decorrer deste item os desafios entre o encontro do desencontro de gerações; aspectos motivacionais pela busca do conhecimento; a educação enquanto formação humana; a dificuldade da geração $Y$ em reconhecer limites que existem nas relações humanas; currículos desenhados de maneira contextualizada.

Diante deste contexto, o docente enfrenta os desafios de ensinar a geração $Y$. A maioria dos docentes da atualidade viveu em um tempo em que o principal meio de comunicação era a televisão e hoje convive com jovens que estão conectados em uma realidade tecnológica e virtual em tempo praticamente integral. Realidade que esses docentes jamais experimentaram em sua infância e juventude, portanto, é de se esperar que o desencontro destas diferenças gerasse problemas e desafios que levam os docentes a reinventar sua formação e seu trabalho (NETO; FRANCO, 2010).

Como lidar com estes jovens da geração Y na educação superior e nos bancos de pós-graduação? Esta geração tem sido conhecida também por geração "troféu", uma alusão por terem sido criados em um ambiente em que ninguém perde, e que todos ganham recompensa só por aparecerem, recebendo constante louvor enquanto eram crianças (CRAMPTON; HODGE, 2009).

A motivação pela busca do conhecimento pode ser intrínseca ou extrínseca. Algumas pessoas criam suas 
próprias recompensas na busca pelo conhecimento ou informação, como a satisfação de sanar a sua curiosidade ou simplesmente o interesse por algum tópico. Outras buscam recompensas externas como elogios ou premiação de qualquer espécie, porém é uma motivação menos efetiva que a recompensa intrínseca (WEILER, 2004). De fato, tem sido negativa a correlação entre as motivações extrínsecas e o desempenho dos estudantes (NEWBY, 1991).

É estabelecido que no ambiente de trabalho, os jovens da geração $Y$ esperam uma comunicação aberta (independente do título ou posição), com constante retorno dos seus supervisores (WOODRUFF, 2009; CRAMPTON; HODGE, 2009). Em se tratando de sala de aula o docente também deve procurar dar sempre o retorno para estes jovens de suas atividades (avaliação formativa), valorizando a sua participação e demonstrando seus erros e acertos nos trabalhos e nas avaliações.

Vale ressaltar que esta geração "troféu" não está apta para receber críticas e, portanto, deve haver uma maior sutileza e habilidade por parte dos docentes em prepará-los para os resultados negativos e críticas construtivas. É parte do trabalho de um mestre esta correção para a melhoria do desempenho e da formação do aluno.

O conhecimento das características desses jovens e a melhor forma para lidar com os seus anseios e defeitos dentro da sala de aula de nível superior, possibilitará a formação de profissionais com melhores habilidades e competências, assim consequentemente para o mercado de trabalho.

Portanto, pensar a educação como um elemento que possibilite a compreensão e o exercício da cidadania. A educação não dever ser vista apenas como um elemento que forma pessoas para o mercado de trabalho, pois segundo menciona Matheus (2013, p. 57):

A auto culpabilização do trabalhador em relação às dificuldades que enfrenta é algo muito interessante para quem quer dar manutenção ao atual status quo. É uma forma interessante de controlar o povo e evitar que ele se revolte contra o que realmente lhes impossibilita ter uma vida melhor.

Uma vez que os jovens da geração $Y$ são independentes, têm altas opiniões de si mesmos e parecem querer tudo, é muito importante oferecer orientação para auxiliálos no seu ingresso ao mundo corporativo. Pois, na maioria das vezes, não há mentores dispostos a orientá-los nas empresas, já que os trabalhadores de gerações anteriores nunca tiveram mentores e também porque acreditam que estes jovens não ficam por 
muito tempo no mesmo emprego (CRAMPTON; HODGE, 2009).

O ambiente de trabalho com serviço competitivo, com foco nas exigências do cliente, necessita padronizar suas práticas e processos. Então, o trabalhador, independente da sua geração, deve ajustarse às necessidades da empresa (CRAMPTON; HODGE, 2009), ou pode correr o risco de não se enquadrar no perfil procurado pelas organizações.

A abordagem tradicional por meio da leitura, ensinamento pela rotina da memorização e outros métodos de classe usados frequentemente, tem favorecido duas áreas da inteligência, a verbal (linguística) e a lógica (matemática). Então, algumas pessoas estariam em desvantagem neste sistema de aprendizagem, como os artistas, que resolvem problemas visualmente, com habilidades visuais (espaciais), ou as que têm que fazer uma atividade para aprender a resolver problemas, com habilidades corporais (motoras).

Somente uma pequena porcentagem da população prefere ler para aprender, por isso poucas pessoas são profissionalmente ligadas à educação ou às bibliotecas (MANUAL, 2002). Os estudantes absorvem apenas $10 \%$ do que leem e de 20 a $30 \%$ do que eles veem. As figuras podem ser a razão dos estudantes preferirem modelos virtuais de informação, como televisão, "internet", vídeos, DVDs e outras origens de informações visuais que podem ser mais efetivas para seus estilos de aprendizagem (WEILER, 2004).

Alunos milênio adotam uma postura muito peculiar e diferente da que seria o ideal para os seus docentes. É bastante comum em sala de aula, estes alunos fazerem diversas coisas ao mesmo tempo e acharem absurdo não poder ouvir mp3, ou usar o celular durante uma aula (BORGES, 2012).

Em uma pesquisa com os docentes de jovens desta geração, a indisciplina se destacou como o aspecto mais negativo desses alunos, que relataram falta de interesse dos alunos e dos pais na educação dos filhos. O docente quer ensinar, precisa ensinar, para melhorar a formação do aluno e para que a escola seja bem conceituada e o aluno "não está nem aí", no dizer dos docentes (ANDRADE; CÁRIA, 2012).

O que se sabe é que existe um estilo de comunicação diferente nos indivíduos da geração $Y$, enquanto nas gerações anteriores, havia comunicação via carta, via telefone e presencial, os jovens da atualidade preferem a comunicação virtual (CRAMPTON; HODGE, 2009).

Os docentes devem procurar maneiras mais eficazes de serem ouvidos, pois ensinar esta geração é um enorme desafio quando há a necessidade de ganhar e prender a sua atenção. Como o tempo gasto 
em sala de aula para eles é desmotivador, então os docentes devem trabalhar com mais envolvimento para que se obtenha um resultado satisfatório no processo de ensino e aprendizagem. As atividades de aprendizagem para esta geração devem ser baseadas em mais prática que buscam associar-se a teoria (BALC; BOZKURT, 2013).

Segundo Lowman (2007), o bom docente deve, além de explicar o conteúdo com clareza, envolver o aluno, usando de sua voz, gestos e movimentos para chamar a atenção dos estudantes e depois mantê-la. Mas atingir este objetivo não é fácil, visto que os alunos podem ter muitos fatores de distração em sala de aula. Além disso, estudos mostram que alunos que trabalham apresentam desempenho inferior, pois têm seu nível de atenção reduzido e menor tempo para os estudos (CUNHA et al., 2010).

Apesar da comunicação oral ainda permanecer nos membros da geração $Y$, ela é totalmente contaminada pelos processos de globalização e de consumo, e também por sua configuração imagética, hipertextual e hipermidiática. Há uma reconfiguração da língua escrita e resistência à leitura tradicional, portanto os livros estão se tornando obsoletos para esta nova geração, pois não oferecem "hiperlinks" para outras consultas, nem imagens, nem sons.

É muito comum os alunos egressos do ensino médio, afirmarem que nunca leram um livro, e apesar de terem grande dificuldade, quase incapacidade, para se expressarem em linguagem escrita, são muito inteligentes e podem criar coisas fantásticas utilizando linguagem multimídia, como música, desenho e imagem (NETO; FRANCO, 2010). Segundo Castanha e Castro (2010, p.31):

Como educadores, sabemos que 0 processo de aprendizagem é relacional e, como tal, precisa estar instituído no coração do currículo. A necessidade do estabelecimento do vínculo é fundamental. O docente precisa conhecer e fazer uso das ferramentas tecnológicas utilizadas pelos alunos. Essa pode ser uma das estratégias de estabelecer esse vínculo.

Como funcionários, os membros da geração $\mathrm{Y}$ consideram desnecessários os treinamentos para melhorar seu desempenho, pois não desenvolvem um compromisso com a organização de longo prazo. Eles não estão cientes da quantidade de aprendizagem que eles precisam. Para esta geração o que irá aprender e para quê servirá em curto prazo é o que importa (BALC; BOZKURT, 2013).

Resultando em mais um desafio a ser pensado pelos docentes e coordenadores de cursos superiores, será possível modificar a matriz curricular de um curso superior, de forma que os estudantes vislumbrem a 
utilização de conceitos básicos do início do curso já de forma aplicada? Como será possível ensinar a aplicação sem a base teórica, que é tão importante na formação do bacharelado ou da licenciatura para o desenvolvimento de um pensamento crítico e formar competências na solução de problemas?

Redesenhar o currículo da educação superior é um imenso desafio, pois as mudanças ali configuradas indicariam a medida efetiva de transformação realizada em qualquer instituição universitária (BERNHEIM; CHAUI, 2008), além disso, as matrizes curriculares dos cursos de graduação seguem o preconizado pelas diretrizes curriculares do Ministério de Educação.

Não é possível afirmar que um simples estágio realizado durante os anos iniciais do curso superior, seria o suficiente para o discente encontrar a aplicação dos conteúdos básicos na prática, sem conhecimentos aprofundados das técnicas praticadas. Além disso, apenas alguns alunos buscam estas atividades extracurriculares. Atividades práticas são sempre bem-vindas neste contexto, porém as práticas das disciplinas básicas podem facilmente entediar o aluno por ele não enxergar uma aplicação imediata.

$\mathrm{O}$ docente sempre deve exemplificar a aplicação do que os estudantes estão aprendendo, isto faz parte da prática docente, porém, como os membros da geração $Y$ são imediatistas, não há como prever que esta atitude alcance os resultados almejados.

Portanto, levando em conta a importância da leitura e da busca da informação para criar um pensamento crítico (WEILER, 2004), talvez a nota do final do semestre (avaliação somativa) seja a única motivação que eles tenham de buscarem o conhecimento necessário, vislumbrando a recompensa que pode ser a nota ou a aprovação.

Porém, como a avaliação somativa tem um caráter classificatório pode levar a uma desmotivação dos discentes que não atingiram os resultados esperados ou ainda a uma evasão escolar. Canen (2001) ainda relata que este tipo de avaliação é combatido por várias teorias, uma vez que desconsidera os aspectos culturais, tão importantes na aprendizagem.

Além disso, como esses alunos pedem retornos constantes e querem resultados imediatos, quando percebem que não estão evoluindo em determinada matéria, logo desanimam e são restritivos aos temas que não Ihes agrada, e como são individualistas não fazem a menor cerimônia em emitir julgamentos sobre seus docentes (BORGES, 2012).

Segundo Borges (2012, p. 77): 
O que se percebe é que esses alunos não apresentam as características desejadas pelos docentes e caracterizam-se, no ambiente educacional, pela crise quando o assunto é autoridade, quando se fala de valores, de ideologias, pela velocidade, inconsistência e fragilidade dos vínculos. Entender essas características do comportamento dos futuros alunos é um desafio para as instituições e também para os docentes.

Muitas vezes, os docentes não entendem as características dos seus alunos do ensino superior e esperam deles o mesmo comportamento que eles tiveram em sala de aula, levando o docente a uma expectativa muito alta em relação ao desempenho dos seus discentes e se decepcionando com as manifestações dos mesmos (PIMENTA, 2008). O docente precisa conhecer o seu aluno e mudar o seu comportamento ou jamais atingirá os objetivos traçados no seu plano de ensino.

\section{SUPERAR OS DESAFIOS EDUCACIONAIS: POSSIBILIDADES}

Existem alguns elementos que podem ser utilizados nas práticas pedagógicas para enfrentar os desafios já relatados neste texto. Longe de ser um manual de práticas e procedimentos para a solução do problema, este trabalho irá propor alguns exemplos de práticas educacionais que podem funcionar na educação da geração milênio.

Ensinar os alunos a usar os meios de comunicação, principalmente a "internet" é de suma importância, pois a "internet" tem conteúdos científicos importantes e de fácil acesso quando comparados às revistas científicas impressas que ficavam armazenadas nas bibliotecas.

Cabe ao docente ensinar o aluno a procurar e separar o que é informação válida e confiável. A tecnologia pode ser um importante instrumento de aprendizagem ou pode ser um instrumento de consumismo e distração com superfluidade. Ensinando como usar esta ferramenta de forma benéfica, também será introduzido nesses jovens uma conscientização e um pensamento crítico. Não é função da "internet" educar, a função de qualquer mídia é apenas a informação, a educação é função do docente e ele pode usar a "internet" como ferramenta para a educação.

A utilização das Tecnologias de Informação e Comunicação por parte do docente pode ser um potencial na educação, porém, este educador deve estar preparado para utilizar-se destes instrumentos para conseguir de forma adequada a socialização do conhecimento e da informação (BARBOSA; FERREIRA, 2013). 
Os docentes precisam estar abertos ao uso dessas tecnologias em salas de aula para que os desafios sejam superados, Santos e Radtke $(2005$, p.332) relatam que:

A realidade de uma instituição de ensino constitui-se de uma estrutura, uma organização de tempo, de espaço, de grade curricular, que, muitas vezes, dificulta 0 desenvolvimento de uma nova prática pedagógica. São amarras institucionais que refletem nas amarras pessoais. Não basta o(a) docente (a) querer mudar. É preciso alimentar a sua vontade de estar construindo algo novo, de estar compartilhando os momentos de dúvidas, questionamentos e incertezas, de estar encorajando o seu processo de reconstrução de uma nova prática. Uma prática reflexiva na qual a tecnologia possa ser utilizada a fim de reverter 0 processo educativo atual.

Vale ressaltar, ainda, que a "internet" nem sempre é uma forma de inclusão, pois ela pode causar a exclusão social na medida em que nem todos os usuários tem um conhecimento aprofundado de como utilizála, nem tampouco está em condições de participar ativamente dos processos de inteligência coletiva (BARBOSA; FERREIRA, 2013). Além disso, no trabalho desses mesmos autores, ficou claro que a maioria dos estudantes acessa a "internet" de casa, isto pode indicar uma falta de equipamentos móveis conectados à "internet".

Portanto, a Instituição de Ensino, antes de rever sua metodologia de ensino, deverá também se preocupar em disponibilizar equipamentos suficientes para os alunos em sala de aula. Segundo Xavier (2011), trata-se de as escolas disponibilizarem para seus docentes e alunos condições tecnológicas razoáveis que viabilizem certas ações pedagógicas e possibilitem uma aprendizagem de acordo com o contexto histórico dos alunos.

A aula deve ser mais participativa para atrair a atenção dos alunos. É possível por meio de projetos interdisciplinares promovem uma atitude investigativa $\mathrm{e}$ protagonista, possibilitando que os estudantes busquem informações relacionadas à vida real. Estabeleçam desta forma conceitos e conexões entre os assuntos tão necessários para o seu processo de formação acadêmica (CASTANHA; CASTRO, 2010). Castanha e Castro (2010, p.36) destacam ainda que:

Além dos elementos conceituais no processo de aprendizagem, o trabalho com projetos interdisciplinares favorece a cooperação, a relação mais solidária com seus pares e a conquista da descentração, tão necessárias para a superação do egocentrismo 
e imediatismo que caracterizam a geração $\mathrm{Y}$.

Como os estudantes universitários são imagéticos, é preciso pensar em como introduzir um pensamento crítico e reflexivo nesses estudantes quando eles observam uma imagem. As escolas devem fazer com que os alunos não sejam apenas receptores de imagens, mas intérpretes e críticos delas, capazes de pensar muito além do que o prazer que elas proporcionam ao serem admiradas.

Não adianta pensar em estratégias de ensino para esta geração, sem lembrar que os docentes precisam estar preparados para repensar e reinventar suas práticas pedagógicas, refletir sua ação, por isso, as Instituições de Ensino devem se preocupar com a formação continuada para que o docente esteja preparado para ensinar de forma diferente da que aprendeu.

Não será difícil para a maioria dos docentes $d a$ geração $X$ introduzir novas tecnologias nas suas aulas, pois estes indivíduos não cresceram conectados, mas convivem com a tecnologia já há vários anos e aprenderam a utilizá-la.

Porém, modificar práticas pedagógicas não é fácil e demanda tempo. Além disso, não deve haver uma mudança brusca no modo de ensinar e sim uma mudança gradativa, com maior participação dos alunos em sala de aula, mais atividades interativas, mais imagens, movimentos e sons, sempre verificando por avaliações formativas o que está funcionando e o que não está dando certo.

É importante lembrar que os docentes não devem em nome do cumprimento de um currículo desconsiderar as mudanças tecnológicas e de gerações. Atualizar o currículo é necessário para que os alunos encontrem um sentido no que estão aprendendo.

\section{CONCLUSÕES}

Ensinar os jovens da geração $Y$ é um grande desafio para os docentes da atualidade, já que os membros da geração $Y$ cresceram em um ambiente histórico-social repleto pelas multimídias. Por isso, é necessário que o docente conheça em primeiro lugar e se identifique com sua profissão, para assim compreender quem são os seus alunos no contexto universitário, o que pensam, como agem, o que almejam e como se relacionam.

Quanto mais trabalhos forem desenvolvidos sobre as características desses jovens, mais informações os docentes terão para se basear e rever suas práticas pedagógicas em sala de aula e não apenas, julgar somente o que os alunos não conseguem apreender. $\mathrm{O}$ saber experiencial docente favorece o refletir nas ações pedagógicas e consequentemente interfere 
no processo de ensino e de aprendizagem (TARDIFF, 2010).

Para esta geração de jovens universitários, há que se privilegiar a participação do aluno buscando alternativas didáticas como resolução de problemas, trabalhos em grupo, elaboração de projetos criativos (maquetes, filmes, teatros e outros do gênero), além do uso das ferramentas multimídia (para uma maior comunicação virtual), podendo resultar em um maior desempenho destes alunos nas atividades acadêmicas.

O docente imbuído do saber profissional, disciplinar, curricular e experiencial, consegue refletir sua prática pedagógica e inovar na sua ação em sala de aula. A formação continuada deve ser proporcionada pelas instituições para seu corpo de docentes, pois a profissão docente é complexa, o que requer aperfeiçoamento constante.

A formação continuada é uma forma de propiciar ao docente refletir sobre suas ações e práticas pedagógicas, é a reflexão-naação (SCHÖN, 1997, p. 83), gerando assim novos conhecimentos para desenvolver-se na sua profissão.

Os docentes envolvidos no processo de ensino e de aprendizagem deverão entender que trabalhar com novos métodos de aprendizagem demanda mais tempo e trabalho. Todavia, mesmo com tantas ferramentas tecnológicas, o docente será sempre o mediador do conhecimento, sem este profissional qualificado a educação de qualidade não se faz.

Esta prática reflexiva que permitem o docente fazer diferente, inovar constantemente, pode ocorrer em diferentes estágios da formação e da prática profissional. Por isso, o conhecimento e a formação para a profissão do docente é e deve ser continuada.

O docente precisa enfrentar e superar os desafios que o exercício da própria profissão exige e das contradições que vive no ambiente de trabalho educacional. Isto contribuirá para refletir sobre suas ações pedagógica e consequentemente, favorecerá e contribuirá no processo de ensino e de aprendizagem para a geração Y.

\section{REFERÊNCIAS}

ANDRADE, N. L.; CÁRIA, N. P. A sala de aula da geração $\mathrm{Y}$ : repensando a formação em serviço para os professores. In: Encontro Nacional de Didática e Práticas de Ensino XVI ENDIPE, Livro 2, p.6723-6735, 2012, Campinas. Anais... Campinas: UNICAMP (Junqueira \& Marin Editores), 2012.

BALC, A.; BOZKURT, S. Job expectations of Generation $X$ and $Y$ Teachers in Turkey. World Applied Sciences Journal, v. 21, n. 4, p. 599-614. 2013.

BARBOSA, J. S. D.; FERREIRA, S. L. Mídias Sociais, Educação e Formação Docente. Interfaces Científicas - Educação, v. 1, n. 2, p. 81-90. 2013. 
BERNHEIM, C. T.; CHAUI, M. Desafios da universidade na sociedade do conhecimento. Brasília: Unesco, 2008.

BORGES, B. S. Mudanças impostas pela Geração " $Y$ " nos contextos político e educacional brasileiro. Cadernos da FUCAMP, v. 11, n. 15, p. 71-81. 2012.

BUCKLEY, M.; FEDOR, D.; VERES, J.; WIESE D.; VE CARRAHER, S. Investigating newcomer expectations and job-related outcomes. Journal of Applied Psychology, v. 83, p. 452461. 1998. http://dx.doi.org/10.1037/0021$\underline{9010.83 .3 .452}$

CANEN, A. Avaliação da aprendizagem em sociedades multiculturais. São Paulo: Papel Virtual, 2001.

CASTANHA, D.; CASTRO, M. B. A necessidade de refletir sobre as estratégias pedagógicas para atender à aprendizagem da Geração Y. Revista de Educação do COGEIME, v. 19, n. 36, p. 28-38. 2010. http://dx.doi.org/10.15599/01044834/cogeime.v19n36p27-38

CERBASI, G.; BARBOSA, C. Mais tempo mais dinheiro: estratégias para uma vida mais equilibrada. 1.ed. Rio de Janeiro: Thomas Nelson Brasil, 2009.

CLARO, J. A. C.; TORRES, M. O. F.; JOÃO, B. M.; TINOCO, J. E. P. Estilo de vida do jovem da "Geração $Y$ " e suas perspectivas de carreira, renda e consumo. In: SEMINÁRIOS EM ADMINISTRAÇÃO - SEMEAD, 13., 2010, São Paulo. Anais... São Paulo: FEA/USP, 2010.

CRAMPTON, S. M.; HODGE, J. W. Generation $Y$ : Unchartered Territory. Journal of Business \& Economics Research, v. 7, n. 4, p. 1-6. 2009.

CUNHA, J. V. A.; CORNACHIONE JUNIOR, E. B.; DE LUCA, M. M. M; OTT, E. Modéstia de Alunos de Graduação em Ciências Contábeis sobre o Desempenho Acadêmico: Uma análise pela ótica da teoria da autoeficácia. In: Congresso USP de Controladoria e Contabilidade, v.10, São Paulo. Anais... São Paulo: USP, 2010.

D'ESPOSITO, J. E.; GARDNER, R. M. university students perceptions of the internet: an exploratory study. The Journal of Academic Librarianship, v. 25, n. 6, p. 456-461. 1999. http://dx.doi.org/10.1016/S00991333(99)00078-6

DICECCO, V. Hey! What's the matter with kids today? Or Managing today's crossgenerational workforce. 2006. Disponível em:

<http://www.sgia.org/feature_articles/kids_t oday_dicecco.htm>. Acesso em: 20 nov. 2013.

FGI. One workplace, four generations: Managing their conflicting needs. Working Well for Managers, n. 7. 2006. Disponível em:

<http://www.mta.ca/hr/managers/workingw ell_sept2004.pdf\#search=\%22Working\%20for \%20managers\%20One\%20workplace\%2C\%20 Four\%20generations\%20FGI\%22>. Acesso em: 20 nov. 2013.

GRIMES, D. J.; BOENING, C. H. Worries With The Web: A Look at Student Use of Web Resources. College \& Research Libraries, 62, n.1, p. 11-23. 2001. http://dx.doi.org/10.5860/crl.62.1.11

HERRING, S. D. Faculty acceptance of the world wide web for student research. College \& Research Libraries, v. 62 , n. 5, p. 251-258. 2001. http://dx.doi.org/10.5860/crl.62.3.251

HOWE, N.; STRAUSS, W. Generations: The History of America's Future, 1584 to 2069. 1.ed. New York: Morrow, 1991.

IBGE. Censo demográfico 2010: Famílias e domicílios, resultados da amostra. 2010. Disponível em: $<\mathrm{ftp}$ //ftp.ibge.gov.br/Censos/Censo_Demogr 
afico_2010/Familias_e_Domicilios/censo_fa m_dom.pdf>. Acesso em: 22 nov. 2013.

KLIKSBERG, B. O contexto da juventude na América Latina e no Caribe: as grandes interrogações. Revista de Administração Pública, v. 40, n. 5, p. 909-942. 2006. http://dx.doi.org/10.1590/S0034-

$\underline{76122006000500008}$

LEITE, C; RAMOS, K. Docência universitária: análise de uma experiência de formação na universidade do Porto. In: CUNHA, M. I. (org). Reflexões e práticas em pedagogia universitária. Campinas: Papirus, 2007, p. 2742.

LOWMAN, J. Dominando as técnicas de ensino. São Paulo: Atlas, 2007.

LUCARELLI, E. Pedagogia universitária e inovação. In: CUNHA, M. I. (org). Reflexões e práticas em pedagogia universitária. Campinas: Papirus, 2007, p. 75-92.

MACEDO, K. C. Valores profissionais da Geração Y: Um estudo sobre a Geração Y e os princípios orientadores em sua vida no trabalho. 2012. 44f. Trabalho de Conclusão de Curso (Graduação em Administração) Universidade Federal do Rio Grande do Sul, Porto Alegre.

MANUAL, K. Teaching information literacy to generation $Y$. Journal of Library Administration, v. 36, n. 1-2, p. 195-217. 2002.

http://dx.doi.org/10.1300/J111v36n01 12

MATHEUS, F. de C. Escolarização e oportunidade de trabalho: uma pequena reflexão sobre um equívoco comum. Colloquium Humanarum, Presidente Prudente, v. 10, n. 2, jul/dez 2013, p. 46-62. Disponível em: <http://revistas.unoeste.br/revistas/ojs/inde x.php/ch>. Acesso em: 11 nov. 2014.
MITCHELL, S. How to Talk to Young Adults. American Demographics, v. 15 , n. 4 , p. 50 54. 1993.

MOSES, M. The $\$ 100$ Billion Allowance: Accessing the Global Teen Market. 1. ed. New York: John Wiley \& Sons, 2000.

MOTTA, P. C.; GOMES, M. Z.; VALENTE, P. Venderam meu futuro: crise e a nova geração. Revista Pensamento Contemporâneo em Administração, v. 3, n. 2, p. 20-34. 2009.

NETO, E. S.; FRANCO, E. S. Os docentes e os desafios pedagógicos diante das novas gerações: considerações sobre o presente e o futuro. Revista de Educação do COGEIME, v. 19, n. 36, p. 9-25. 2010. http://dx.doi.org/10.15599/01044834/cogeime.v19n36p9-25

NEWBY, T. J. Classroom motivation: strategies of first-year teachers. Journal of Educational Psychology, v. 83, n. 2, p. 195200. 1991. http://dx.doi.org/10.1037/0022$\underline{0663.83 .2 .195}$

NOGUEIRA, D. R.; CASA NOVA, S. P. C.; CARVALHO, R. C. O. O bom docente na perspectiva da geração $\mathrm{Y}$ : uma análise sob a percepção dos discentes de Ciências Contábeis. Enfoque: Reflexão Contábil, v. 31, n. 3, p. 37-52. 2012.

PIMENTA, S. G.; ANASTASIOU, L. G. C. Docência no Ensino Superior. São Paulo: Cortez, 2008.

PNUD. Programa das Nações Unidas para o Desenvolvimento (PNUD). Relatório do Desenvolvimento Humano 2010. Nova York, 2010.

ROCHA-DE-OLIVEIRA, S.; PICCININI, V.C.; BITENCOURT, B.M. Juventude, gerações e trabalho: é possível falar em geração $Y$ no Brasil? O\&S, v. 19, n. 62, p. 551-558. 2012. 
SANTOS, F. A. S. N. Juventude, consumo e globalização: uma análise comparativa. 2004. 391 f. Tese (Doutorado em Gestão) Instituto de Superior de Ciências do Trabalho e da Empresa, Lisboa.

SANTOS, B. S.; RADTKE, M. L. Inclusão digital: reflexões sobre a formação docente. In: PELLANDRA, N. M. C., SCHLUNZEN, E. T. M.; JUNIOR, KLAUSS S. Inclusão digital: tecendo redes afetivas / cognitivas. Rio de Janeiro: DP\&A, 2005.

SANTROCK, J. Child Development. 8. ed., Dubuque: McGraw-Hill, 1998.

SCHÖN, D. Formar professores como profissionais reflexivos. In: NÓVOA, A. (coord). Os professores e a sua formação. Lisboa: Dom Quixote, 1007, p. 77-91.

SIMÕES, L., GOUVEIA, L. Targeting the Millennial Generation. III Jornadas de Publicidade e Comunicação. A Publicidade para o consumidor do Séc. XXI. Porto: Universidade Fernando Pessoa (UFP), 10 de abril de 2008.

TARDIF, Maurice. Saberes docentes e formação profissional. 11aㅡ ed. Petrópolis. Rio de Janeiro: Vozes, 2010.

TROSSET, C. C. Obstacles to open discussion and critical thinking: the Grinnell College study. Change, v. 30, n. 5, p. 44-50. 1998. http://dx.doi.org/10.1080/000913898096026 $\underline{42}$

WEILER, A. Information-seeking behavior in generation $Y$ students: motivation, critical thinking, and learning theory. The Journal of Academic Librarianship, v. 31, n. 1, p. 46-53. 2004.

http://dx.doi.org/10.1016/i.acalib.2004.09.00 $\underline{9}$

WOODRUFF, C. Generation Y. Training Journal. p. 31-35. 2009.
XAVIER, A. C. Letramento digital: impactos das tecnologias na aprendizagem da Geração Y. Calidoscópio, v.9, n.1, p. 3-14. 2011. http://dx.doi.org/10.4013/cld.2011.91.01

YOUNG, N. J.; SEGGERN, M. V. General Information Seeking in Changing Times: A Focus Group Study. Reference \& User Services Quarterly, v. 41, n. 2, p. 159-169. 2001.

Recebido para publicação em 14/11/2014

Revisado em 11/12/2014

Aceito em 19/03/2015 